\title{
Correction to: Solving a nonlinear variation of the heat equation: self-similar solutions of the second kind and other results
}

\author{
RODRIGO MENESES (D) AND OSCAR ORELLANA
}

\section{Correction to: J. Evol. Equ.}

$$
\text { https://doi.org/10.1007/s00028-019-00480-1 }
$$

In the original publication, the second author's surname was incorrect. The correct name should be Oscar Orellana.

The original article has been corrected.

Publisher's Note Springer Nature remains neutral with regard to jurisdictional claims in published maps and institutional affiliations.

\author{
Rodrigo Meneses \\ Escuela de Ingeniería Civil, Facultad de Ingeniería \\ Universidad de Valparaíso \\ General Cruz, 222 \\ Valparaíso \\ Chile \\ E-mail: rodrigo.meneses@uv.cl \\ Oscar Orellana \\ Departamento de Matemáticas \\ Universidad Técnica Federico Santa María \\ Avenida España 1680 \\ Valparaíso \\ Chile
}

The original article can be found online at https://doi.org/10.1007/s00028-019-00480-1. 